\title{
A Soft Tooling process chain employing Additive Manufacturing for injection molding of a 3D component with micro pillars
}

\author{
Zhang, Yang; Pedersen, David Bue; Segebrecht Gøtje, Asger ; Mischkot, Michael
}

Published in:

Journal of Manufacturing Processes

Link to article, DOI:

10.1016/j.jmapro.2017.04.027

Publication date:

2017

Document Version

Peer reviewed version

Link back to DTU Orbit

Citation (APA):

Zhang, Y., Pedersen, D. B., Segebrecht Gøtje, A., \& Mischkot, M. (2017). A Soft Tooling process chain employing Additive Manufacturing for injection molding of a 3D component with micro pillars. Journal of Manufacturing Processes, 27, 138-144. https://doi.org/10.1016/j.jmapro.2017.04.027

\section{General rights}

Copyright and moral rights for the publications made accessible in the public portal are retained by the authors and/or other copyright owners and it is a condition of accessing publications that users recognise and abide by the legal requirements associated with these rights.

- Users may download and print one copy of any publication from the public portal for the purpose of private study or research.

- You may not further distribute the material or use it for any profit-making activity or commercial gain

- You may freely distribute the URL identifying the publication in the public portal 


\section{A Soft Tooling process chain employing Additive Manufacturing for injection moulding of a 3D component with micro pillars}

Yang Zhang* ${ }_{1}$, David Bue Pedersen ${ }_{1}$, Asger Segebrecht Gøtje ${ }_{1}$, Michael Mischkot ${ }_{1}$, Guido Tosello $_{1}$

1. Department of Mechanical Engineering, Technical University of Denmark

Produktionstorvet, building 427A, room 322

Kgs.Lyngby DK 2800

Denmark

Keywords

Additive manufacturing, DLP, Injection Moulding, 3D Part, Micro Pillars, Soft Tooling

*Corresponding author: yazh@mek.dtu.dk

\section{Abstract}

The purpose of the research presented in this paper is to investigate the capability of a soft tooling process chain employing Additive Manufacturing (AM) for preproduction of an insert with micro features by injection moulding. The Soft Tooling insert was manufactured in a high temperature photopolymer by Digital Light Processing (vat photopolymerization). The mold cavity was formed by two insert halves, by design; both inserts have four angled tines, with micro holes ( $\varnothing 200 \mu \mathrm{m}, 200 \mu \mathrm{m}$ deep) on the surface. Injection molding with polyethylene was used with the soft tool inserts to manufacture the final production components. The diameter and height of the pillars that were replicated on the molded components were characterized by means of a 3D profilometer. The influence of the injection molding parameters on the replication was evaluated using a 2-levels DOE of three factors. The uniformity of the pillars are also evaluated regarding the diameter and height.

\section{Introduction}

Functionalities realized by micro-structured surfaces are applied in many areas, for example in the field of cell biology [1] [2], optical elements [3], etc. The micro structured surface considered in this work is of special interest due to the fact that it can promote cell proliferation and enhance the bonding between the proliferated tissues and the molded surface, provided the micro-features are arranged according to a certain pattern [4][5].

Replication of micro features onto polymer can be achieved by different moulding process precisely [6]. One of the latest research is from Metwally et al, who reported their work on replication of micro and sub-micro features on flat surface and high fidelity between the molded parts and the mold was 
obtained [7]. Most of the research focus on flat surface or surface with single curvature. For instance, S. Bruening et al. implemented a cylinder processing system [8]. Nian et al. showed in [9] that micro features could be replicated by hot embossing on a curved surface. However, the process chain for producing complex parts with microstructures on surface is rarely reported, although most of the reallife devices that demand that the micro structuring on the surface has a three-dimensional (3D) geometry. The challenges lie in the fabrication of a 3D mold cavity with micro features on the surface, and in the replication process from the mold. For instance, demolding may fail for features with high aspect ratio on a complex surface, e.g. non-perpendicular to the demolding direction. Bissacco et. al have reported their work of replication of nano pattern on a 3D mold insert by injection molding. The results shows that the specific nano pattern was successfully generated on polymer parts using the 3D mold inserts [10]. In the author's previous work, It was demonstrated that when the aspect ratio is 0.5 , it was possible to obtain $\varnothing 4 \mu \mathrm{m}$ PEEK pillars on a wall parallel to demolding direction by injection molding [11]. In this paper, the investigated product is a ring with four tines, each characterized by having an angle of 60 degrees. This geometry has been studied in [12], where micro features were introduced by implementing pre-fabricated nickel plates, and micro pillars $(\varnothing 4 \mu \mathrm{m})$ with aspect ratio of 0.5 was obtained by silicone rubber injection molding on the tines.

This paper focuses on the replication of microstructures on complex surface created by a soft tooling process chain. This method replaces the steel mold cavities in the injection molding machine with a set of inserts made by vat photopolymerization based AM. Compared to metal AM, the photopolymer based AM technologies can achieve higher precision. In the case of Image mask projection systems, the resolution can be as high as $6 \mu \mathrm{m}$ [13]. Among technologies that are able to create microstructures on the surface of a 3D cavity, additive manufacturing has the advantage in computer-aided design for surface topography. Moreover, the machining time and cost is reduced significantly compared to conventional tooling processes based on CNC machining. Processes involving AM is suitable for products requiring a high flexibility in design freedom. Lantada et al. has described a process chain that starts from AM prototypes in order to obtain designed surface texture, and then coating techniques was employed for obtaining metallic mold inserts for injection molding [14]. Polymer parts produced by AM has been proved directly applicable as mold inserts. For example as reported in [15] and [16]. Inserts manufactured from carbon fiber reinforced photopolymer has withstood up to 2500 injection molding cycles for polyethylene before noticeable mold deterioration was observed [17]. This soft tooling process chain is suitable for production in intermediate production volumes (e.g. from $1000-$ 10.000 cycles by injection molding).

\section{Experiments}

\subsection{Inserts fabrication by additive manufacturing (AM)}

Two inserts are required to form the cavity. An EnvitionTEC perfactory ${ }^{\circledR} 3 \mathrm{MML}$ with an enhanced resolution module (ERM) was used in order to produce the parts. The Perfactory $3 \mathrm{MML}$ is with a $\mathrm{f}-85$ $\mathrm{mm}$ lens capable of delivering a voxel-size of down to $16 \mu \mathrm{m}$ [18]. The photopolymer used was a proprietary methyl methacrylate and acrylamide monomer/oligomer blend, photo initiated by a titanium dioxide based photoinitiator. The resin has a tensile strength of $56 \mathrm{MPa}$, elongation at break of 3.5\%, a flexural strength of $115 \mathrm{MPa}$, flexural Modulus of $3350 \mathrm{MPa}$ and a heat deflection temperature of $140^{\circ} \mathrm{C}[19]$. 

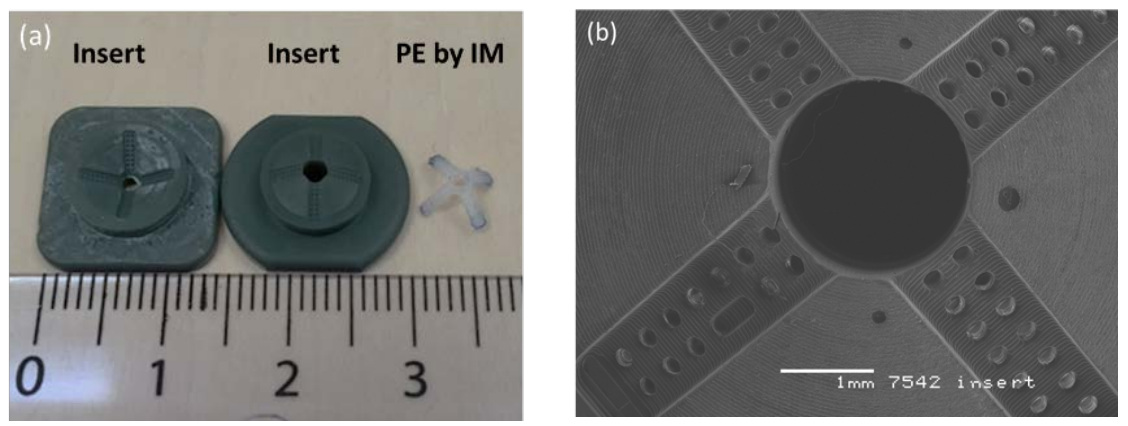

Figure 1 (a) Inserts produced by additive manufacturing process and one polyethylene (PE) replica produced by injection molding using the two inserts which forms the mold cavity. (b) The surface of the insert: individual layers from the AM process are visible. $\varnothing 200 \mu \mathrm{m}$ holes were printed on the four tines.

Figure 1 (a) shows the inserts fabricated by AM and the PE parts produced by injection molding. Two rows of circular holes were vertical to the surface on the tines (Figure 1 (b)). The nominal dimensions has been chosen so that when the holes are resolved into the $16 \mu \mathrm{m}$ voxel-size of the AM machine tool, it will yield a roundness of 0.8 which correlates to nominal geometry that is $200 \mu \mathrm{m}$ in diameter and $200 \mu \mathrm{m}$ in depth. These features were spaced with a center- to-center distance $400 \mu \mathrm{m}$. A mark was designed on both the inserts, which is an elongated hole on both sides, so that the same tine can be tracked for investigation. The layers structure that was formed in the AM process are clearly visible.

\subsection{Injection molding (IM)}

Injection molding tests were operated by an Arburg (370 A $600-70)$ equipped with a micro unit. The screw diameter was $8 \mathrm{~mm}$ and the clamping force was $100 \mathrm{KN}$. Polyethylene (PE Purell 1840) was chosen as the material for injection molding mainly due to its low processing temperature. Figure 2 illustrates how the inserts was mounted on the mold. Figure 3 illustrates the demolding step. The pillars were not parallel to the demolding direction, they may risk breaking during demolding.

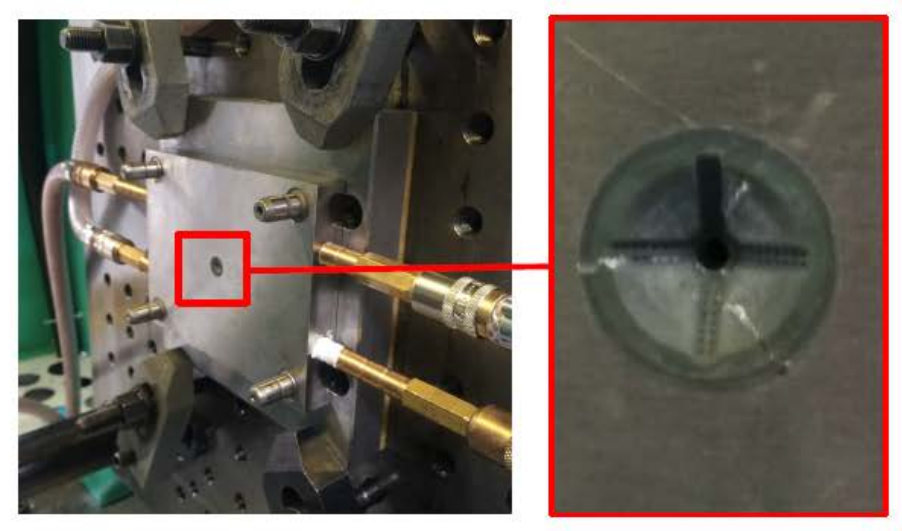

Figure 2 The mold plate (injection side) with an AM insert mounted for injection molding. 


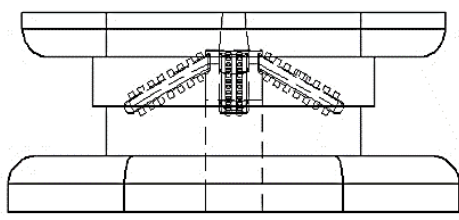

(a)
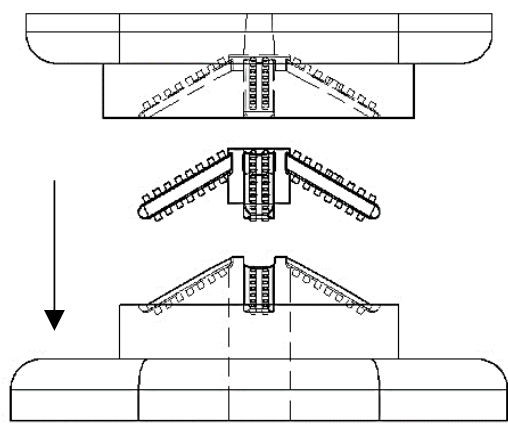

(b)

Figure 3 The demolding step in injection molding. (a): molds close (b) molds open for demolding. Pillars are not parallel to the demolding direction.

A two-level full factorial design of experiments (DOE) with 3 factors were operated in order to evaluate the influence from the injection molding (IM) parameters on the replication. The tested IM parameters are listed in Table 1. For all the $2^{3}=8$ runs, the injection molding was operated until one insert cracked or otherwise stopped at 100 cycles. For each run, a new pair of inserts were used. Most of the runs reached more than 80 cycles. After a limited amount of runs, the injection side insert cracked due to the very thin area in the center. The replication degree was calculated by dividing the dimensions from the pillars by the dimensions of hole on the corresponding insert.

Table 1 The tested injection molding parameters in the design of experiments (DOE).

\begin{tabular}{|c|c|c|c|}
\hline & \multicolumn{3}{|c|}{ Injection molding parameters } \\
\hline$\#$ & Control Factors & Low & High \\
\hline 1 & Mold temperature $\left[{ }^{\circ} \mathrm{C}\right]$ & 30 & 60 \\
\hline 2 & Melt temperature $\left[{ }^{\circ} \mathrm{C}\right]$ & 175 & 185 \\
\hline 3 & Injection speed $[\mathrm{mm} / \mathrm{s}]$ & 38 & 65 \\
\hline
\end{tabular}

\subsection{Dimension measurements}

The micro features on the inserts and the IM parts were measured using an Olympus Lext OLS 4100 laser scanning digital microscope with assistance of the SPIP ${ }^{\circledR}$ software for post-processing of data. The detailed method was described in [12]. The obtained PE parts were grouped into batches of 10 pieces in each run, i.e. 1-10 was the $1^{\text {st }}$ batch, $11-20$ was the $2^{\text {nd }}$ batch, until the last piece in the run. One random sample in each batch was measured on the top and back sides; two areas with different distance to the gate "near the gate" and "far from the gate" on both sides of the tine were measured for comparison. Figure 4 illustrates the measured sides (on the inserts) and the areas. Four holes/pillars on each area were measured. The average dimensions of the four hole/pillars were used to characterize the measured area. Both the depth/height and the diameter of the features were analyzed. The measurement repeatability for the pillars using this instrument is $8.1 \mu \mathrm{m}$ for the diameter measurements and $1.6 \mu \mathrm{m}$ for the height measurements. 
(a)

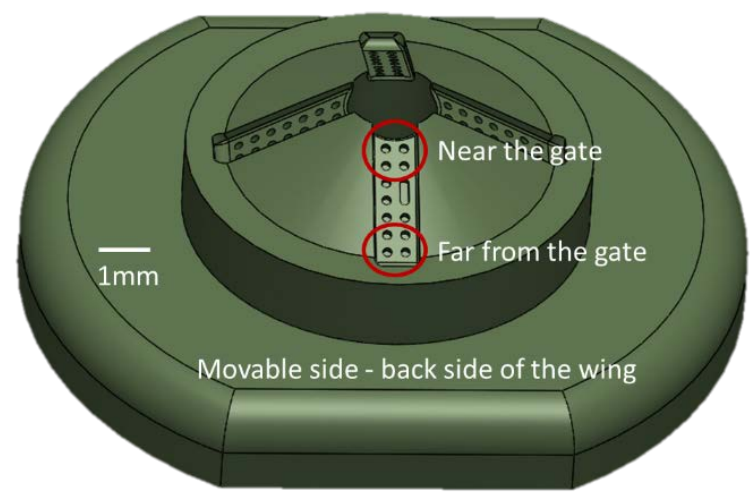

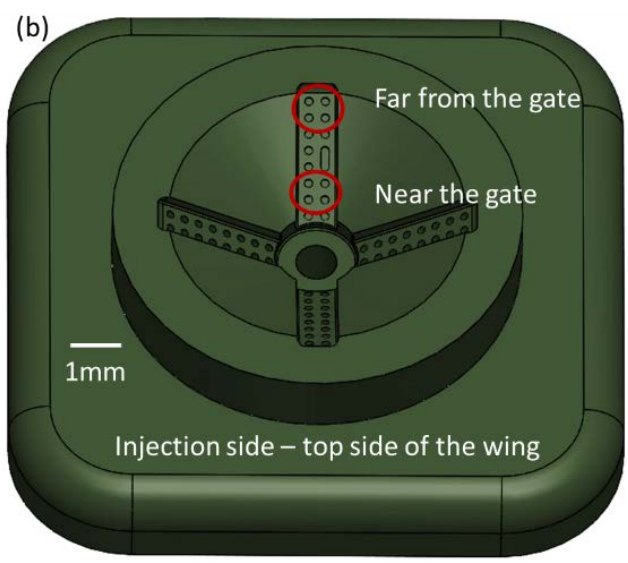

Figure 4 The measured area are highlighted on the CAD image of the inserts. The movable side insert correspond to the backsides of the tines; the injection side corresponds to the top sides of the tines. The injection gate locates at the center. Two areas with difference distance to the gate, "Far from the gate" and "Near the gate" are compared in the research.

\section{Analysis}

\subsection{Replication propagation over 100 shots}

The demolding was successful, in the sense that no pillar breaking was observed in all the studied samples. Most of the runs reached more than 80 cycles.

Run 4 ( $T_{\text {Mold }} 60^{\circ} \mathrm{C}, T_{\text {Barrel }} 175^{\circ} \mathrm{C}$, and $V_{\text {injection }} 65^{\circ} \mathrm{C}$ ) was chosen to illustrate how the replication would propagate along the 100 cycles of injection molding. One randomly selected sample was measured in each batch. The replication degree of the pillars height and diameter at four positions (backside-far from the gate, backside-near the gate, topside-far from the gate and topside-far from the gate) was plotted to batch in Figure 5 and Figure 6. Table 2 lists standard deviation for each position on the parts.

Along the 100 cycles, the replication degree was stable at each position for both height and diameter of the pillars, considering the standard deviation for the manufacturing process. This observation is also confirmed by the observation to the dimension of the holes on the inserts.

Table 3 lists the dimension change of the holes on the corresponding inserts after injection molding, while the standard deviation values from the operator repeatability measurements are provided on the side for comparison. It can be concluded that the dimensions of the holes on inserts did not change during the 100 cycles. Similar facts were observed for the other runs.

The pillars on position of far-from-the-gate are notably lower than on the top side due the pressure drop. The side view of a tine in Figure 7 also illustrates this phenomenon visually. Regarding the diameter, the difference from positions are not as prominent as for the height (Figure 6).

In the displayed chart and plots, some of the replication degrees (pillar dimension / mold dimension) are higher than 1, which means the pillars should be larger than the holes on mold. It is believed to be caused by deformation of the pillars during demolding. 


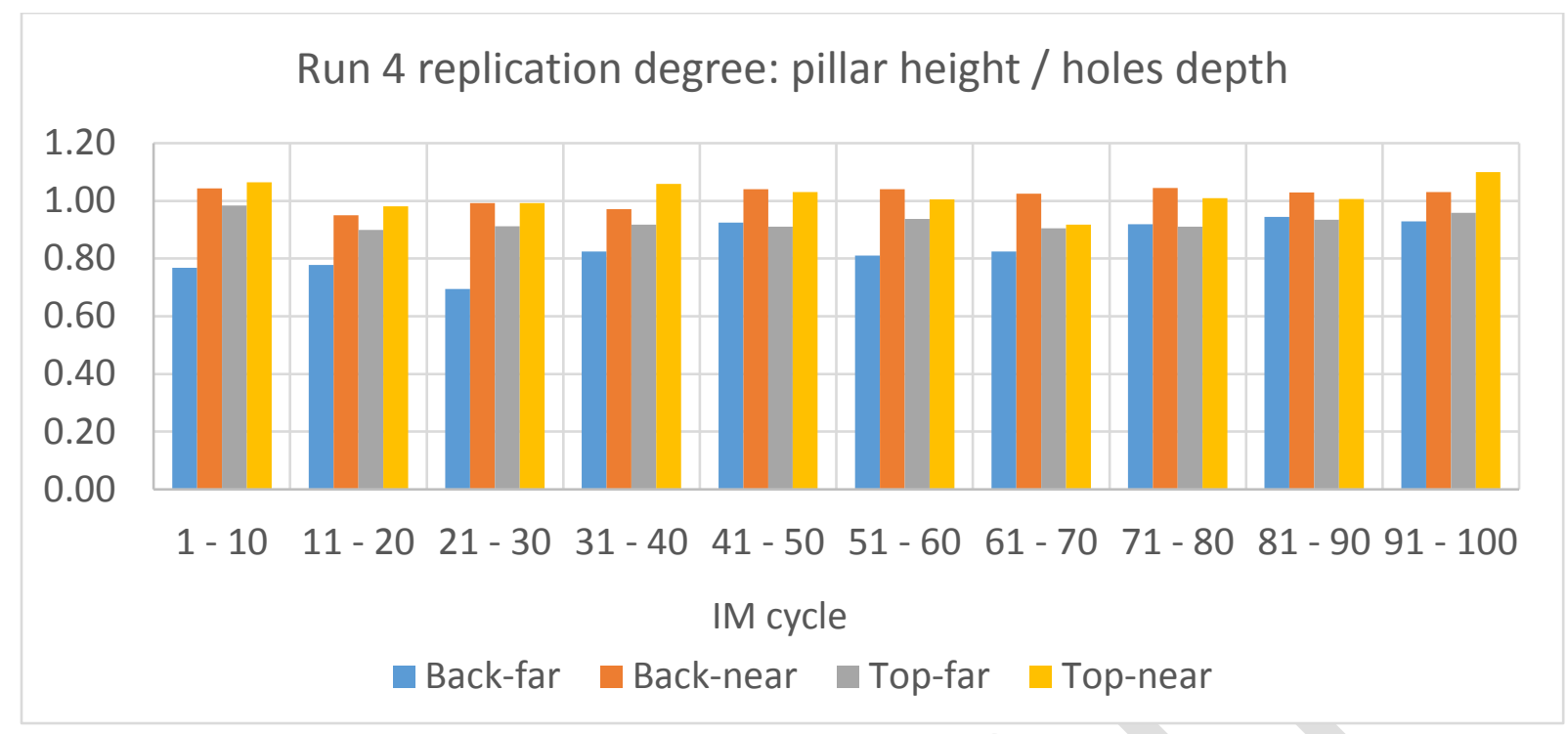

Figure 5 Replication degree of the pillar height (height of the pillar/depth of the hole). The mean value of the replication degree at the four positions was displayed in each batch in Run $4\left(T_{\text {Mold }} 60^{\circ} \mathrm{C}, T_{\text {Barrel }} 175^{\circ} \mathrm{C}\right.$, and $\left.V_{\text {injection }} 65^{\circ} \mathrm{C}\right) .1$ randomly selected sample was measured in each batch.

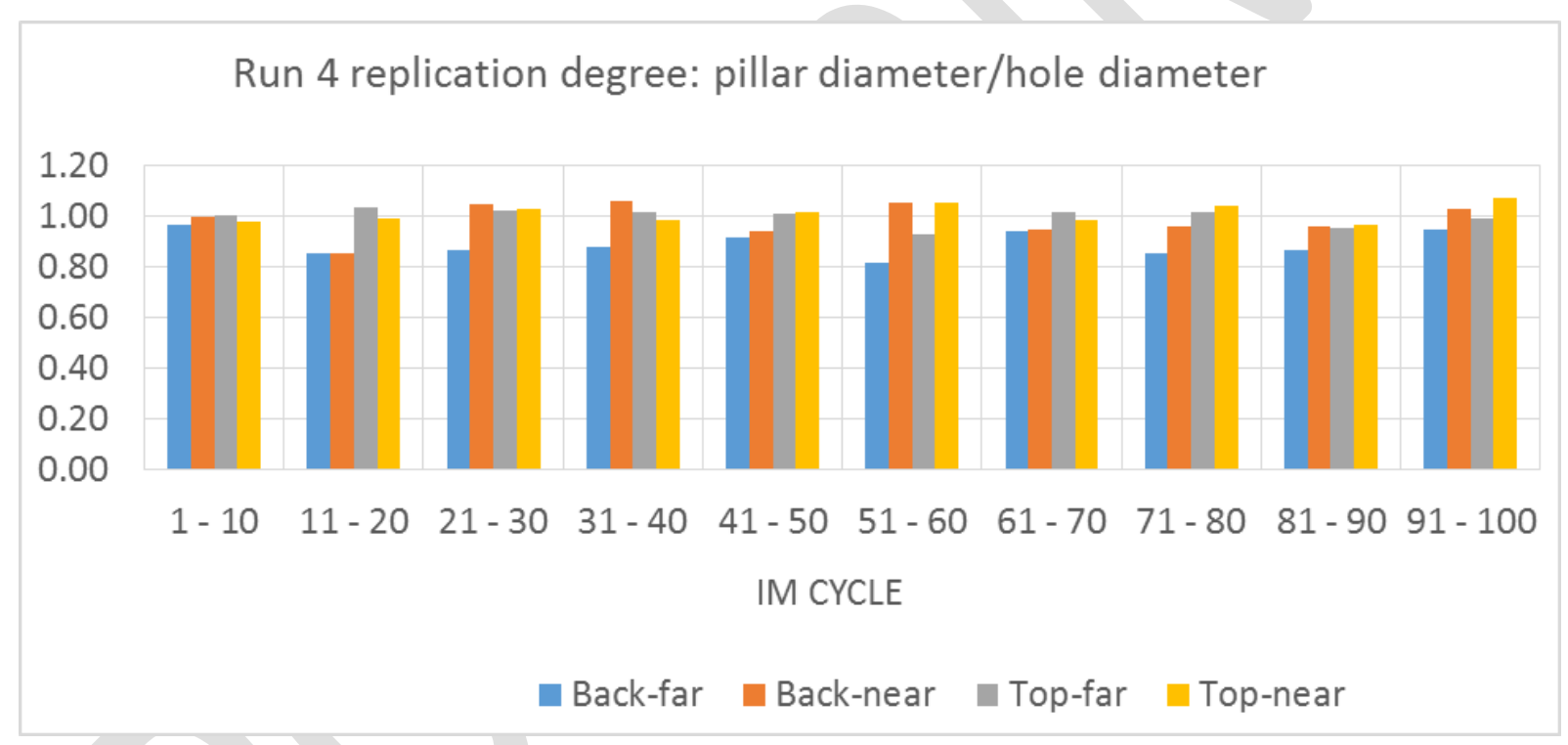

Figure 6 Replication degree of the pillars diameter (diameter of the pillar/diameter of the hole) in Run $4\left(T_{\text {Mold }} 60^{\circ} \mathrm{C}, T_{\text {Barrel }}\right.$ $175^{\circ} \mathrm{C}$, and $\left.V_{\text {injection }} 65^{\circ} \mathrm{C}\right)$. 


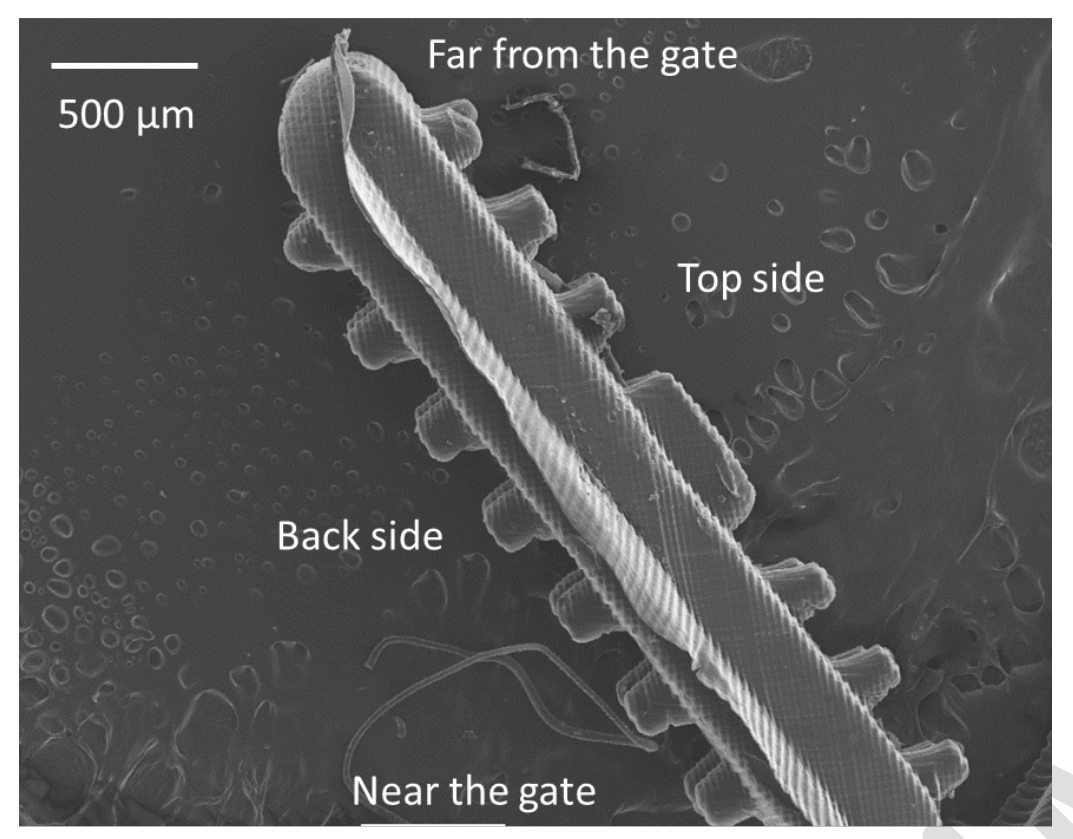

Figure 7 Side view of one random tine. The investigated four positions are labeled on the image.

Table 2 Manufacturing uncertainty for run 4 at the four measured positions.

\begin{tabular}{|c|c|c|c|c|}
\hline Positions & $\begin{array}{c}\text { Standard } \\
\text { deviation of } \\
\text { diameter in } \\
\text { Run 4 }(\mu \mathrm{m})\end{array}$ & $\begin{array}{c}\text { Standard } \\
\text { deviation of } \\
\text { height in Run 4 } \\
(\mu \mathrm{m})\end{array}$ & $\begin{array}{c}\text { Standard } \\
\text { deviation of } \\
\text { diameter for all } \\
\text { the runs }\end{array}$ & $\begin{array}{c}\text { Standard } \\
\text { deviation of } \\
\text { height for all the } \\
\text { runs }\end{array}$ \\
\hline Mold & 10.4 & 14.6 & 19.7 & 13.7 \\
\hline Back-near & 14.1 & 5.7 & 14.7 & 7.1 \\
\hline Top-far & 8.0 & 4.6 & 14.6 & 12.5 \\
\hline Top-near & 7.7 & 9.0 & 15.7 & 19.6 \\
\hline
\end{tabular}

Table 3 The dimension difference on inserts for Run 4 after and before injection molding. The standard deviation of repeatability measurements for inserts is for comparison. The same inserts were measured 7 times in 4 days in order to estimate the operator repeatability.

\begin{tabular}{|c|c|c|c|c|}
\hline & \multicolumn{2}{|c|}{$\begin{array}{c}\text { Inserts difference after and before IM in } \\
\text { Run 4 }\end{array}$} & \multicolumn{2}{c|}{$\begin{array}{c}\text { Standard deviation in operator repeatability } \\
\text { test }\end{array}$} \\
\hline Positions & Diameter $(\mu \mathrm{m})$ & Depth $(\mu \mathrm{m})$ & Diameter $(\mu \mathrm{m})$ & Depth $(\mu \mathrm{m})$ \\
\hline Top-Far & 1.1 & -0.7 & 0.5 & 1.4 \\
\hline Top-Near & -0.3 & -2.6 & 1.4 & 1.2 \\
\hline Back-Far & 1.7 & 1.4 & 0.5 & 0.7 \\
\hline Back-Near & 3.3 & -2.8 & 2.7 & 3.9 \\
\hline
\end{tabular}

\subsection{Influence of injection molding parameters}

In order to evaluate the influence from the injection molding parameters, based on the previous conclusion that the replication was stable within each single run, the DOEs analysis utilized all the data within each run. The variation among batches were ignored.

Figure 8 and Figure 9 show the main effects plots for the replication degree of height and diameter respectively. The position relative to the gate has a major effect for the replication of height, but not 
for the diameter, which agrees with the previous conclusion in session 3.1. This is because the pillars are filled one by one along the flow direction, i.e. along the tine. For the lateral replication, the total flow length is until the end of the tine, while to fill the pillars vertically, the total flow length is until the top of the pillars, which is much shorter, and the complete filling of a pillar is at the end of the flow length. Therefore, the pressure drop during lateral replication is much less compared to that needed along the vertical direction. This phenomenon was also observed in micro-pillar injection molding using nickel cavity in previous research [12], though the dimension was much smaller $(\varnothing 4 \mu \mathrm{m})$ than this study.

The injection speed also has a strong influence. Improved filling of the holes requires lower injection speed. The polymer flow has been visualized in [20] that at lower injection speed it is steadier; because at higher speed, the pressure in the cavity increases dramatically at the flow front and the viscosity of the polymer flow increases as well, therefore the holes are less filled regarding both the height and diameter at high injection speed.

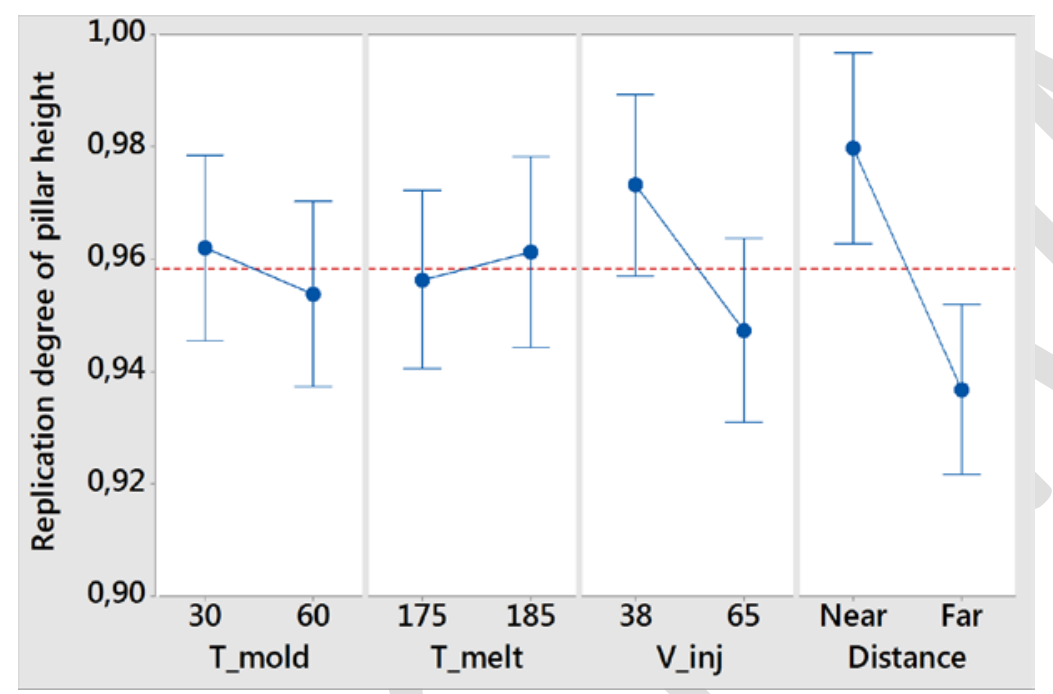

Figure 8 Main effects plots for the replication degree of pillars height (95\% confidence interval for the mean). The red dashed line shows the mean value of all the data. Standard deviations are used as interval bars. (Replication degree $=$ height of the pillar/depth of the hole).

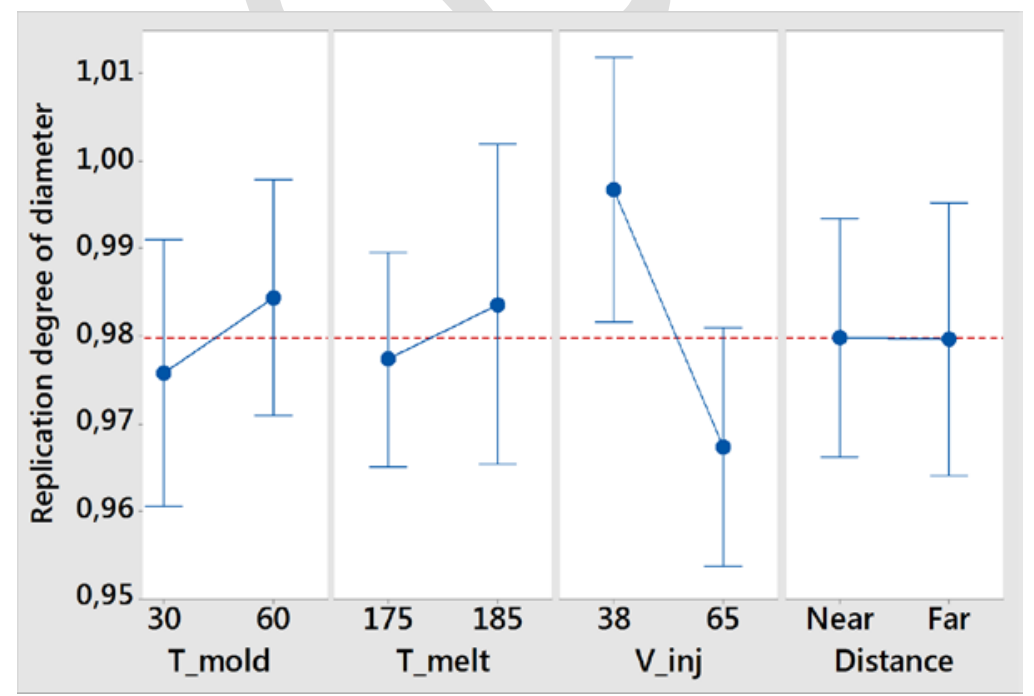

Figure 9 Main effects plots for the replication degree of pillar diameter (95\% confidence interval for the mean). The red dashed line shows the mean value of all the data. Standard deviations are used as the interval bars. (Replication degree = diameter of the pillar / diameter of the hole). 
Mold temperature and melt temperature were less influential. However, the mold temperature tends to interact intensely with the other factors, as shown by the interaction plots for the replication degree of pillar height in Figure 10, especially with the injection speed and the position relative to the gate (near and far in the plot). At lower $\mathrm{T}_{\text {mold }}$, lower injection speed lead to better filling. This is because at lower injection speed, the flow behavior is dominated by the heat exchange between the polymer flow and the mold. It is worth to mention that at high $T_{\text {mold, }}$, the pillars are lower at the far end of the tine, which is opposite to what is expected; however, this should be analyzed together with Figure 13, the plots for standard deviation of the pillars. At high $T_{\text {mold }}$, the standard deviation when it is far from the gate is also high, due to bigger chance to be deformed.

Regarding the replication of diameter, the injection molding setup has actually less influence, since the variation in the interaction plot in Figure 11 has a relative small range. Moreover, the injection speed has an obvious interaction with the other factors. When it is far from the gate, lower injection speed can significantly improve the replication degree for diameter. Better filling can be obtained at high melting temperature and low injection speed, due to the low viscosity of the polymer flow under high temperature. Nevertheless, when the injection speed is high, the viscosity augment can no longer be compensated by the effect from temperature increase.

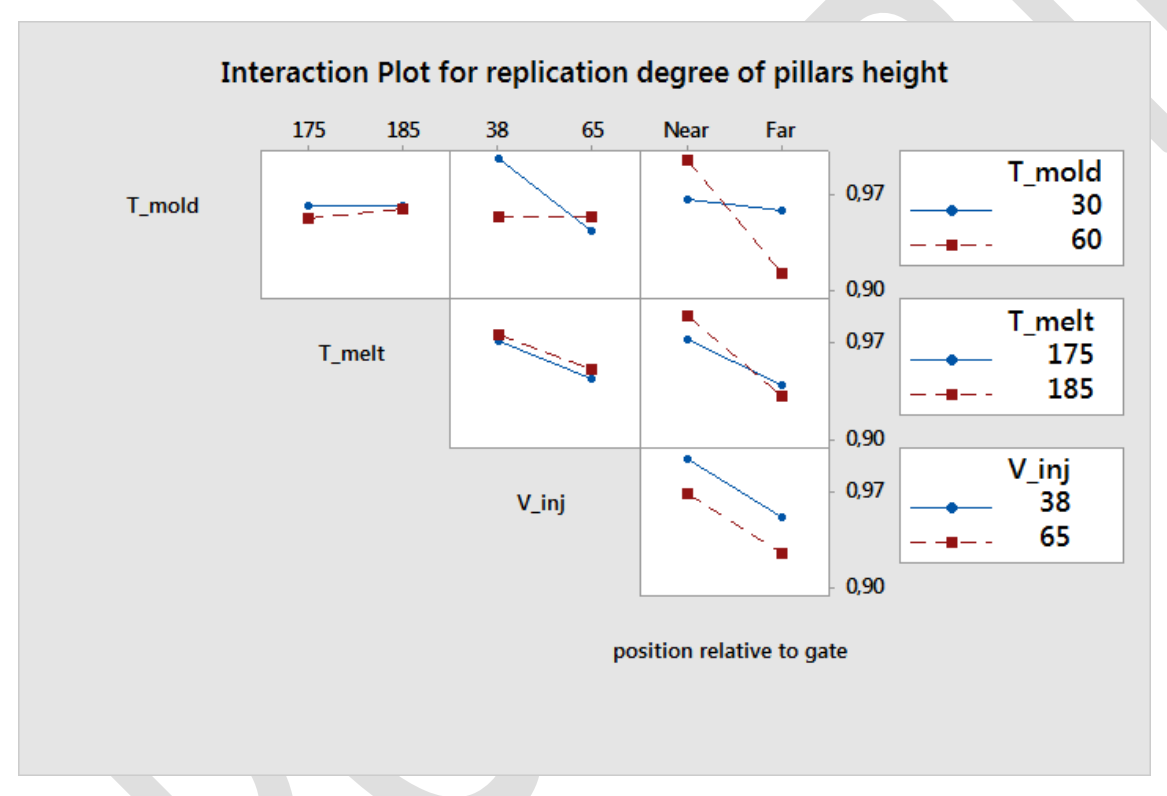

Figure 10 The interaction plots for the replication degree of the pillars height (Replication degree = height of the pillar/depth of the hole). 


\section{Interaction Plot for replication degree of diameter}

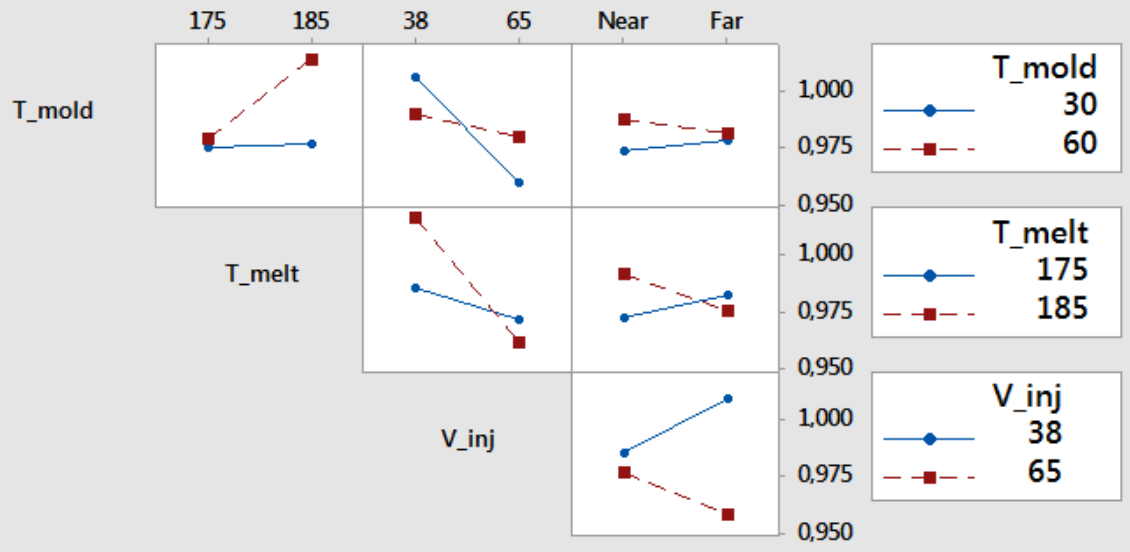

Position relative to gate

Figure 11 The interaction plots for the replication degree of the pillars diameter (Replication degree = diameter of the pillar/diameter of the hole).

\subsection{Uniformity of the pillars}

The uniformity of the pillars dimension is of special interest because high uniformity is required in order to promote cell growth in biomedical applications [4]. Especially the height is required to be unchanging all over the surface. Figure 10 and Figure 11 have shown that at lower $\mathrm{T}_{\text {Mold, }}$, the difference of dimensions between the positions is smaller. The uniformity is also assessed by the standard deviation of the four measured pillars at each position. Figure 12 shows that when far from the gate, pillars tend to be more diverse. This is presumed to be caused from the pillars deforms during demolding under high mold temperature. In order to reduce the deviation at the end far from the gate, low mold temperature can be applied according to the interaction plots in Figure 13, even though the diameter diversity near the gate is increased obviously, and the replication degree for diameter is lower as well at low mold temperature.

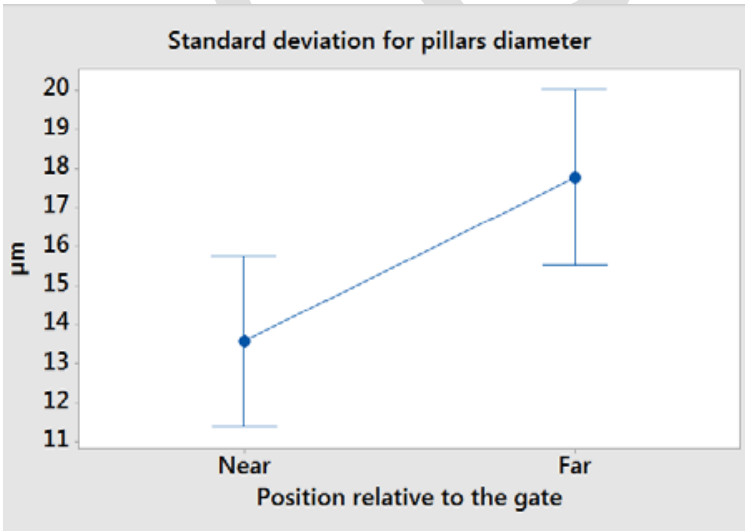

(a)

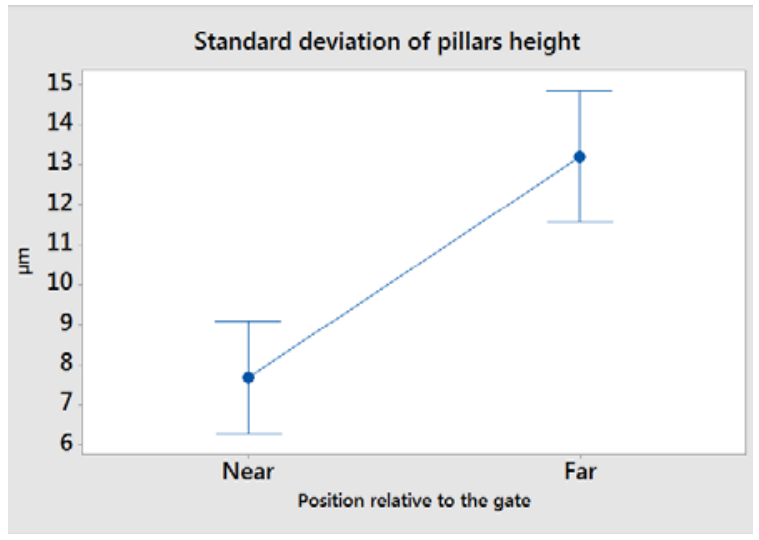

(b)

Figure 12 The main effects plots for standard deviation of: (a) pillars diameter and (b) pillars height. The standard deviation of the dimensions is used to assess the uniformity of the pillars. 


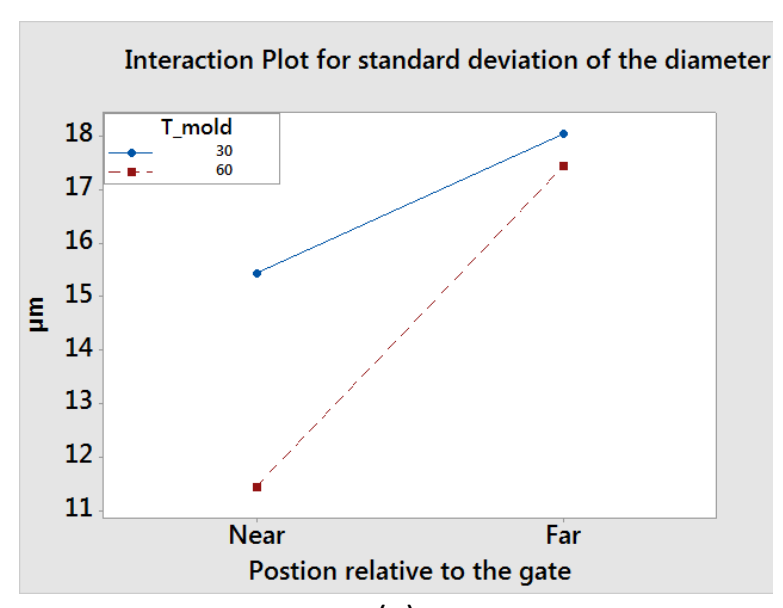

(a)

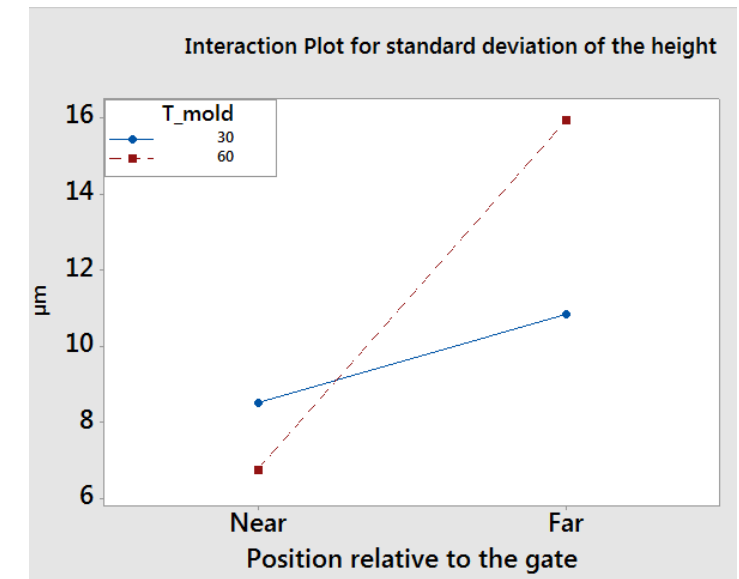

(b)

Figure 13 Interaction plot for the standard deviation of: (a) the diameter; (b) the height. The standard deviation of the pillars dimension is used to assess the uniformity of the pillars.

\section{Conclusion}

In order to study the feasibility of micro structuring on the surface of a complex geometry, the present research has established a process chain that uses AM at the micro dimensional scale to produce such structured surface as alternative to conventional tooling methods such as complex CNC micro machining.

Inserts for forming an injection molding cavity were produced by additive manufacturing process. The target product is a three-dimensional micro component having four-tine each tilted with an angle of

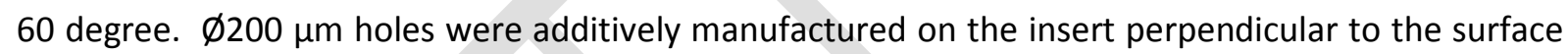
with aspect ratio of 1 . A two-level three-factor full factorial DOE was conducted in order to evaluate the influence of injection molding parameters on the durability and replication properties of the inserts. Tool life up to a maximum of 100 cycles were conducted for each injection molding runs. The major conclusions from the presented research are:

- In the explored process window, most of the runs reached more than 80 cycles, confirming the tool life of the AM inserts was not influenced in the explored process window.

- Micro pillars were successfully replicated on the tines. The pillars were not parallel to the demolding direction. Along the 100 cycles by injection molding, no change was observed regarding the diameter and the height of the pillars on each observed position. It was demonstrated the micro holes on the AM inserts were not plastically deformed by the injection molding process.

- The pillars positioned far from the gate were lower than those placed near the gate, confirming typical behavior of polymer flow that increases its viscosity at increasing flow length in the cavity, hence decreasing the surface replication when filling micro features in the depth direction.

- The diameters of the pillars at far from the gate and near the gate were not different, confirming the possibility to obtain consistent dimensional accuracy of micro features in the lateral direction. This is because the pillars are filled one by one along the flow direction. The total flow length is until the end of the tine, while to fill the pillars, the total flow length is until the top of the pillars. Therefore, the pressure drop laterally is much less compared to along the vertical direction.

- When the mold temperature is lower, the average diameter and height of the pillars are more similar on far from the gate and close to the gate; meanwhile the diversity at the far end is less regarding the height, even though the replication degree of diameter were slightly lower in this case. 
- Lower injection speed is recommended in order to obtain a high replication degree regarding the height and the diameter of the pillars. This confirms that at high injection speed, the increased air pressure inside cavity has a governing effect that increases the viscosity of the polymer flow dramatically.

\section{Acknowledgement}

This paper reports work undertaken in the context of the project "Advanced surface treatment for implantable medical devices" funded by Innovation Fund Denmark.

\section{References}

[1]. Doan, N. M., Qiang, L., Li, Z., Vaddiraju, S., Bishop, G. W., Rusling, J. F., \& Papadimitrakopoulos, F. (2015). Low-Cost Photolithographic Fabrication of Nanowires and Microfilters for Advanced Bioassay Devices. Sensors, 15(3), 6091-6104. doi:10.3390/s150306091

[2]. Lucchetta, G., Sorgato, M., Zanchetta, E., Brusatin, G., Guidi, E., Di Liddo, R., \& Conconi, M. T. (2015). Effect of injection molded micro-structured polystyrene surfaces on proliferation of MC3T3-E1 cells. Express Polymer Letters, 9(4), 354-361. doi:10.3144/expresspolymlett.2015.33

[3]. Hu, H., Tian, H., Shao, J., Ding, Y., Jiang, C., \& Liu, H. (2014). Fabrication of bifocal microlens arrays based on controlled electrohydrodynamic reflowing of pre-patterned polymer. Journal of Micromechanics and Microengineering, 24(9), 095027. doi:10.1088/0960-1317/24/9/095027.

[4]. Kolind, K., Dolatshahi-Pirouz, A., Lovmand, J., Pedersen, F. S., Foss, M., \& Besenbacher, F. (2010). A combinatorial screening of human fibroblast responses on micro-structured surfaces. Biomaterials, 31(35).

[5]. Wilkinson CD., Riehle M, Wood M, Gallagher J, Curtis a. S. The use of materials patterned on a nano- and micro-metric scale in cellular engineering. Mater Sci Eng C. 2002;19(1-2):263-269. doi:10.1016/S0928-4931(01)00396-4.

[6]. Hansen HN, Hocken RJ, Tosello G. Replication of micro and nano surface geometries. CIRP Ann. - Manuf. Technol. 2011;60(2):695-714. doi:10.1016/j.cirp.2011.05.008.

[7]. Metwally, K., Barriere, T., \& Khan-Malek, C. (2016). Replication of micrometric and submicrometric structured surfaces using micro-injection and micro-injection compression moulding. International Journal of Advanced Manufacturing Technology, 83(5-8), 779-789. doi:10.1007/s00170-015-7602-4

[8]. Bruening S, Hennig G. Surface structuring of metals and non-metals for printing tools and embossing dies with an ultrafast ps-laser machining system. In: SPIE. Vol 9351. ; 2015:935112. doi:10.1117/12.2075631.

[9]. Nian, S. -C. 2014. "Novel Embossing System for Replicating Micro-Structures on Curved Surfaces." International Polymer Processing 29 (3). CARL HANSER VERLAG: 364-70. doi:10.3139/217.2790

[10]. Bissacco, G., Biondani, F. G., Tang, P. T., Mischkot, M., Hansen, H. N., Zhang, Y., \& Ravn, C. (2015). Application of Functional Nano-Patterning to Polymer Medical Micro Implants. Proceedings of the 4m/icomm2015 Conference. doi:10.3850/978-981-09-46098118

[11]. $\quad$ Zhang Y., Hansen H.N.; Sørensen S., "Injection molding of micro pillars on vertical side walls using polyether-ether-ketone (PEEK)", Proceeding of 11th International Conference on Micro Manufacturing, ICOMM, Orange County, California, USA, March 2016

[12]. $\quad$ Zhang $\mathrm{Y}$; Mischkot M; Hansen HN; Hansen $\mathrm{P}$, "Replication of microstructures on three-dimensional geometries by injection moulding of liquid silicone rubber" , Proceedings of the 15th International Conference on Metrology and Properties of Engineering Surfaces, ASPE, March 2015, ASPE, Charlotte, NC, USA 
[13]. Envisiontec Perfactory MML with ERM. Technical Specifications Document no. MKMCS-P3MiniMulti-V01-FN-EN, EnvisionTEC GmbH

[14]. Diaz Lantada, A., Piotter, V., Plewa, K., Barie, N., Guttmann, M., \& Wissmann, M. (2015). Toward mass production of microtextured microdevices: linking rapid prototyping with microinjection molding. International Journal of Advanced Manufacturing Technology, 76(5-8), 1011-1020. doi:10.1007/s00170-014-6333-2

[15]. Volpato, N., Solis, D. M., \& Costa, C. A. (2016). An analysis of Digital ABS as a rapid tooling material for polymer injection moulding. International Journal of Materials and Product Technology, 52(1-2), 3-16.

[16]. Mischkot, M, Hansen, HN \& Pedersen, DB 2015, Additive manufacturing for the production of inserts for micro injection moulding. in Proceedings of Euspen's 15th International Conference \& Exhibition.

[17]. Hofstätter, T., Mischkot, M., Pedersen, D. B., Tosello, G., \& Hansen, H. N. (2016). Evolution of Surface Texture and Cracks During Injection Molding of Fiber-Reinforced, Additively-Manufactured, Injection Molding Inserts. In Proceedings of ASPE Summer Topical Meeting 2016: Dimensional Accuracy and Surface Finish in Additive Manufacturing.

[18]. https://envisiontec.com/wp-content/uploads/2016/09/MK-MCS-P3MiniMulti-V01-FNEN.pdf last-accessed-date: 24-11-2016,

[19]. https://envisiontec.com/wp-content/uploads/2016/09/MK-MTS-HTM140IndustrialIVV01-FN-EN.pdf last-accessed-date:24-11-2016

[20]. Jiang K, Zuo J, Yang L, Wang L, and Wang M. (2016). "Visualization Analysis on Polymer Filling Behavior of Injection Molding of Ring-Shaped Workpieces." Gaofenzi Cailiao Kexue Yu Gongcheng/Polymeric Materials Science and Engineering 32 (1). Chengdu University of Science and Technology: 120-24. 